\section{Research Square}

\title{
ICT Adoption and Environmental Sustainability: Thresholds From the Lower and Lower-Middle-Income Countries
}

Mouna AMARI ( $\sim$ amarimouna86@gmail.com )

University of Gabes: Universite de Gabes

Anis JARBOUI

Normandie Université: Normandie Universite

\section{Research Article}

Keywords: ICT, Environment, Quality, Sustainability Policy, GMM Estimation

Posted Date: February 9th, 2021

DOI: https://doi.org/10.21203/rs.3.rs-157112/v1

License: (c) (i) This work is licensed under a Creative Commons Attribution 4.0 International License. Read Full License 


\section{Abstract}

This paper aims to study the relationship between ICT readiness, use, and intensity, and environmental sustainability factors in the lower and middle lower-income countries from 2012-2018. ICT readiness, use, and intensity are measured with the impact of ICT on access to basic services, phone penetration, and internet penetration, while $\mathrm{CO} 2$ emissions per capita, fossil fuel energy consumption, and methane emissions are used as indicators for air pollution. To achieve this goal, the system two steps GMM estimation was performed which thresholds are computed contingent on the validity of tested hypotheses. The results demonstrate that increasing ICT readiness, use, and intensity in lower and lower-middle-income countries enhance environmental sustainability by decreasing $\mathrm{CO} 2$ emissions and energy consumption.

\section{Introduction}

Sustainable development is an increasingly important concern in the world. The public authorities have been proposed many measures to encourage it to be taken into account by society and government. ICTs have become an essential component of modern life in developed and LMICs alike. Technological innovation reduces the resource of air pollution by promoting cleaner production methods which can enhance economic growth (Belloumi., 2009; Sarkodieb, 2019; Omri \& Tarek, 2020; Solomon \& Klyton, 2020). Government authorities suggest for firms to employ integrated production technologies to reduce the negative environmental effects of $\mathrm{CO} 2$ emissions. They demonstrate that replacing the traditional production system with cleaner technologies can diminish air pollution. Despite the international efforts, the implementation of integrated production technologies still hampered by difficulties linked to problems of cost, coordination, and inertia of skills and the productive organization of companies (Balsalobre, 2015); (Khurshid, 2019). Air pollution, climate change, and globalization are three major concerns characterizing the current world economy (Atici, 2012; Omri et al., 2015). Controlling for air pollution represents a very important challenge to achieve the goal of a sustainable environment as presented by Sustainable Development Goals to create a green economy; (Akinyemi, 2018; Asongu \& Odhiambo, 2019). Recently, further studies provide evidence that net outputs from green economic growth are not sufficient to moderate the growing climate pollution. Thus, the consequences of FDI inflows on increasing carbon emissions become a worldwide subject of great importance (Hao \& Liu, 2015; Demena \& Afesorgbor, 2020).

The argument of this research on enhancing information technology for a sustainable environment in lower and middle lowerincome countries is inspired by important factors in the scholarly and policymaking debate.

Firstly, recently, there have been growing opportunities for inhabitants of low and middle low-income countries to use it. These technologies have been experiencing a growing diffusion, whose speed varies significantly in different countries and for diverse tools. Regarding the case of mobile phones, it has been unexpectedly fast and socially widespread. Jointly with the emerging of locally-developed ICT-based applications, this phenomenon has lately renewed the attention of researchers towards ICTs and their potential impact on environmental quality by reducing air pollution.

Secondly, the attendant literature on environment quality has fundamentally focused on: (i) the relationship between $\mathrm{CO} 2$ emissions and ICT penetration in general. Within this framework: (Usman, Ozturk, \& Hassan, 2020) are concerned with how enhancing ICT penetration in sub-Saharan Africa (SSA) can be a key solution towards environmental sustainability by diminishing CO2 emissions; Omri and Tarek (2020) demonstrated that good governance and technological innovation match the foreign direct investment to moderate carbon emissions in twenty-three emerging economies for the period 1996-2014.

Thirdly, the purpose of this study is to complement this current literature by examining how developing ICT adoption and especially the access to the internet in the basic services can affect air pollution. Hence, this paper provides new evidence that sheds light on the role that technology adoption plays in mediating the influence of growth, remittances, education quality on reducing air pollution. To increase the policy relevance of the research, we explore whether there exist technology adoption thresholds. This relationship may be contingent on ICT indicators, where the technological environment promotes the reduction of air pollution after ICT access in basic services; mobile phone and internet penetration exceed a certain threshold level.

As we have noted, the objective of this study is to explore the conditional effects of good governance and ICT adoption on mitigating $\mathrm{CO} 2$ and carbon dioxide emissions to afford opportunities for a green economy in developing countries. Overall, this 
research aims to answer the following question: What minimum thresholds are needed for ICT adoption in the low and lower midincome countries to establish environmental sustainability?

The theoretical underpinning supporting the key role of ICT in improving environmental quality is consistent with the environmental Kuznets curve that supports the hypothesis that there is an inverted $\mathrm{U}$-shaped association between ICT adoption and $\mathrm{CO} 2$ emissions. These emissions are estimated to increase air pollution but at a developed stage of ICT readiness and use, $\mathrm{CO} 2$ emissions may decrease (Akbostanci and Turut-Asi Tunc, 2009; Diao et al., 2009; He and Richard, 2010; (Ahmed \& Ozturk, 2018) (Usman, Ozturk, \& Hassan, 2020) ). Accordingly, empirical findings of the previous papers recommended the need to establish exactly thresholds at which macroeconomic factors can either positively or negatively influence environmental sustainability. Therefore, while this research supports the EKC hypothesis, it also gives more clarification to informs policymakers on thresholds of ICT adoption and use in the basic services.

Our paper is structured as follows. The second section outlines the theoretical framework and presents related literature. The objective of the third section is to explain the methodology. In the fourth section, we present the empirical results and discussions. The paper concludes with policy implications and future research directions.

\section{Theoretical Framework And Related Literature}

\section{2 - 1 ICT and economic growth: the production theory}

Governments around the world call for action to ensure Sustainable Development Goals. They call poor, rich, and middle-income countries to encourage prosperity while protecting the planet (Del Giudice et al., 2019; Zhang et al., 2020; Usman et al., 2020)). They are aware of reducing poverty must be through the economic growth channel and by many others social protection policies including inclusive education, health for all people, social protection, job opportunities, and environmental protection (Tchamyou et al., 2019; Omri, 2020). Nevertheless, with the emergence of the environmental quality challenge as a sustainable goal, the focus of the recent papers has progressively switched to think about how technology adoption and use must consider the harmonization of the economy and environment.

According to the previous studies, ICT value-added suggests that ICT influences productivity for the developed countries but not for developing countries. Recently, researchers provide strong evidence that the developing countries have continued investing in their ICT infrastructure which proposes that ICT development enhanced productivity. Also, authors relying on multi-country surveys found that ICT help in reducing emissions by building smart cities and digital production systems. Overall, the results of these analyses show that digital transformation help in creating an environmentally sustainable society.

Additionally, the literature related to the new theory of growth support that technological change is of critical significance to deal with the polluted environment (Weitzman, 1997). As we can see, the existing literature has been focused on this association by exhibiting that the cost of controlling greenhouse gas (GHG) emissions cannot be kept at a rational level without relying on a collection of technologies that go far beyond what is presently offered. In this context, it is argued that there is a range of reasons throughout we can appreciate the importance of technological innovation in dropping GHG, explicitly: exploiting more and more energy-efficient production technologies, changes in the fuel mix, and the installation of end-of-pipe technology which is considered as the most considerable of the three (Bruyn and Sander, 1997). Correspondingly, Jones (2002) argues that investments in R\&D and technological transformation can be a solution to moderate $\mathrm{CO} 2$ emissions and fight against air pollution. Fan et al. (2006) used a STIRPAT model in diverse income countries during the period 1975-2000 to study the variables linked to $\mathrm{CO} 2$ emissions. The empirical findings of this study provided that the impact of technology adoption on $\mathrm{CO} 2$ emissions varies across the various stages of economic growth. Later Kumar and Managi (2010) investigate the linkage between environmental degradation and ICT innovation, they used data for eighty developed and developing economies. The findings of this study reveal that ICT adoption decreases emissions in developed economies, but increased them in most developing ones.

\section{2-2 Economic growth and $\mathrm{CO} 2$ emissions: environmental Kuznets curve}

The empirical literature has given conflicting results on the association of ICT and growth. For example,(Amari., Baklouti, \& Mouakhar, 2020) found that technology adoption is positively associated with economic growth(Usman, Ozturk, \& Hassan, 2020)

Page 3/17 
measured by GDP growth rate in international comparative evidence. The environmental Kuznets Curve (EKC) hypothesis proposes that the pollution level firstly is completely and positively associated with economic growth. Besides, emissions intensity is connected to economic growth. Additionally, technology development guided the economy to change the traditional manufacturing production system to the smarter one (Amri, 2018). Thus, this change to industry 4.0 will mitigate the $\mathrm{CO} 2$ emissions intensity and as a result, increase energy efficiency. It was considered the year 2019 as the second warmest year on record and the end of the warmest decade (2010-2019) ever recorded. Carbon dioxide (CO2) levels and other greenhouse gases in the atmosphere rose to new records in 2019. Hence, previous studies have confirmed that climate change is touching the majority of countries around the world. It is negatively linked to economic growth and the well-being of people. While it is expected that greenhouse gas emissions will drop about 6 percent in 2020 as a result of the COVID-19 pandemic due to travel bans and economic slowdowns, this result is only provisional. Climate change is not on pause. Once the global economy begins to recover from the pandemic, emissions are expected to return to higher levels.

Sustainable development and environmental protection require more penetration of a good communication tool that enables to diminish the informational knowledge lacks that are linked with environmental change. $\mathrm{CO} 2$ emissions contribute to environmental degradation or air pollution. Besides in this paper, the air pollution caused by $\mathrm{CO} 2$ emissions, fossil fuel energy consumption, and methane emissions will be employed as proxies for environmental degradation. This study aims to determine how increasing information and communication technology adoption can affect the emission such as $\mathrm{CO} 2$.

Previous researchers have found that monitoring environmental governance, environmental management needs a good communication tool. Also, the latest ICT literature is reliable with the findings that compared to other more advanced economies in the world (Asia, Europe \& North America) where ICT is attaining high levels, there is more room for ICT diffusion in SSA. To achieve sustainable development goals (SDGs), policymakers have to deal with sobering policy challenges for sustainable development, like environmental pollution and climate change. In their study (Asongu et al., 2018) provided evidence that the governance of energy use in SSA is a very urgent objective to attain economic growth because of the persistent energy crisis in the sub-region and the non-effective energy management. Besides, (Anyanwu \& Erhijakpor, 2014) confirm that in most African countries, the management of energy is characterized by inefficiency. For example, in Nigeria (the most populous country in Africa), a high number of government resources are using fossil fuels, as a substitute for investing in renewable energy. The use of power generators has contributed to the restoration of energy supply faults and shortfalls, which comprise about three-quarters of the world's greenhouse gas emissions and have brought on global warming. Besides, enhancing ICT reduces $\mathrm{CO} 2$ emissions which can enhance environmental protection. Also, ICT can decrease the costs related to transactions and travel which are linked with the CO2 emissions in households and firms (Asongu \& le Roux, 2017; Higon DA, 2017; Lahouel et al., 2019).

This research takes further steps and aims to fill the gap in the current debate. It builds on the most recent studies, namely those of (Asongu \& le Roux, 2017; Amri, 2017; Ahmed \& Ozturk, 2018) Arif, 2020; Omri \& Tarek, 2020), whilst including more countries in the analysis. Furthermore, this paper aims to explore the net effects of ICT on environmental sustainability by examining how enhancing ICT affects environmental change through the reduction of $\mathrm{CO} 2$ emissions. Whereas human development and socioeconomic benefits associated with ICT have been substantially documented in the existing literature, we contribute to this stream of occupied literature by assessing how ICT access in basic services can be consolidated for environmental sustainability. Besides, the accessibility of ICT services in the lower and middle-lower countries reach first the urban, better off, and educated groups, while the urban poor and rural areas are less implicated and their ability to entirely profit from ICTs is restricted (Das et al., 2018).

\section{Methodology And Data Collection}

\subsection{Data collection}

The data used in this paper consist of 57 countries in lower and lower-middle-income countries[1] over the period 2012 - 2016. The choice of such a period is imposed by the availability of data when the research was conducted. Similarly, to the previous studies, we collected data from different sources (Asongu \& le Roux, 2017; Tchamyou, 2019; Omri \& Tarek, 2020; Solomon \& Klyton, 2020). As a result, we obtained a balanced panel with 285 observations. To assess the relationship between these variables, a dynamic generalized method of moments (GMM) was used. The different sources of data and a short definition of all the variables used in this paper are disclosed in Table 1. Countries included in this sample are "Armenia, Bangladesh, Benin, Bhutan, Bolivia, Burkina

Page $4 / 17$ 
Faso, Burundi, Cambodia, Cameroon, Cape Verde, Chad, Côte d'Ivoire, Egypt, El Salvador, Ethiopia, Gambia, Georgia, Ghana, Guatemala, Guinea, Guyana, Haiti, Honduras, India, Indonesia, Kenya, Kyrgyz Republic, Lao PDR, Lesotho, Liberia, Madagascar, Malawi, Mali, Mauritania, Moldova, Morocco, Mozambique, Myanmar, Nepal, Nicaragua, Nigeria, Pakistan, Philippines, Rwanda, Senegal, Sierra Leone, Sri Lanka, Swaziland, Syria, Tajikistan, Timor-Leste, Uganda, Ukraine, Vietnam, Yemen, Zambia, and Zimbabwe". Following the current debate, we control for trade openness, population growth, GDP growth, education quality, and regulation quality.

Table 1. Variables definition and source

\begin{tabular}{|llc|}
\hline Variable & Definition & Source \\
\hline CO2EM & "CO2 emissions (metric tons per capita)" & WDI \\
\hline FOSSIL & "Fossil fuel energy consumption (\% of total)" & WDI \\
\hline METHANE & "Methane emissions (metric tons of CO2 equivalent per capita)" & WDI \\
\hline INTERNET & Internet penetration & WDI \\
\hline MOBILEPHONE & Mobile phone penetration & WDI \\
\hline ICTBASIC & Impact of ICTs on access to basic services & WDI \\
\hline TRADEOP & Trade openness & WDI \\
\hline GROWTH & GDP growth & WDI \\
\hline POPGROW & Population growth & GRTE \\
\hline QES & Quality of education system & WGI \\
\hline RQ & "Regulation quality (estimate): measured as the ability of the government to formulate and & implement sound policies and regulations that permit and promote private sector development" \\
\hline
\end{tabular}

Before the hypotheses were tested, we examine the descriptive statistics of the variables listed in Table 2. Summary statistics and the correlation matrix have been respectively presented in Tables 2-3.

Table 2. Descriptive statistics 


\begin{tabular}{|c|c|c|c|c|c|c|}
\hline Variable & Obser & Mean & Std. Dev. & Min & Max & Shapiro-Wilk \\
\hline CO2 emissions & 285 & 0.88159 & 0.8693 & 0.0270 & 6.487 & $0.7267 * \star \star$ \\
\hline Fossil fuel energy consumption & 285 & 50.6828 & 18.874 & 4.5734 & 98.488 & $0.94645^{\star \star \star}$ \\
\hline Methane emissions & 285 & 0.93164 & 0.4002 & 0.2788 & 2.81177 & $0.75799 \star \star \star$ \\
\hline Internet penetration & 285 & 15.88425 & 14.411 & 0 & 56.8 & $0.89694^{\star \star \star}$ \\
\hline Mobile phone penetration & 285 & 73.44091 & 37.820 & 0 & 175.30 & $0.98659 * \star \star$ \\
\hline Impact of ICTs on access to basic services & 285 & 4.067677 & 0.9027 & 1.9250 & 6.3335 & $0.94508 * * \star$ \\
\hline Trade openess & 285 & 0.943272 & 0.6316 & 0 & 4.0934 & $0.79764 * \star \star$ \\
\hline GDP growth & 285 & 2.091886 & 8.5107 & -27.234 & 121.7 & $0.39577 * \star \star$ \\
\hline Population growth & 285 & 5.79897 & 5.6156 & -0.0443 & 37.77 & $0.80826 * \star \star$ \\
\hline Quality of education system & 285 & 3.123776 & 1.0940 & 0 & 4.6631 & $0.84688^{\star * \star}$ \\
\hline Regulation quality & 285 & -0.56074 & 0.4765 & -1.9031 & 0.9339 & $0.97807 * \star \star$ \\
\hline
\end{tabular}

Notes: Obser=observations, Std.dev: standard deviation, Min= Minimum, Max=Maximum.

\subsection{Methodology: Identification, simultaneity, and exclusion restrictions}

This paper adopts the GMM estimation for different reasons (Blundell, 1998; Asongu , 2018; Tchamyou, 2019a; Amari et al, 2020).

The first argument for adopting a GMM estimation is the higher number of periods for each country in our sample. The crosssections are exceeding the period. The estimation was conducted for five periods from 57 countries. We employ a balanced panel dataset of annual periodicity over the period 2012-2016. To give reassurance of the goodness of fit information, the explanatory capacity of the models was verified. The model often has a dynamic effect. It is closely connected to its earlier value. Thus, it has been reported in the recently empirical studies that researchers should consider the dynamic effect when conducting times series estimation. This is usually established by adding a lagged dependent variable as an explanatory in the model. Hence, the correlation matrix shows that the environmental indicators are persistent. Thus, the above equations are deduced as follow:

$$
\begin{aligned}
& \operatorname{COCO}_{i, t}=\sigma_{0}+\sigma_{01} \mathrm{CO}_{i, t-\tau}+\sigma_{2} I C_{i, t}+\sigma_{3} I C I C_{i, t}+\sum_{h=1}^{5} \delta_{h} W_{h, i, t-\pi}+\vartheta_{i, t}(1) \\
& \operatorname{Co}_{i, t}-\operatorname{Co}_{i, t-\tau}=\sigma_{1}\left(C O_{i, t-\tau}-C O_{i, t-2 \tau}\right)+\sigma_{2}\left(I C_{i, t}-I C_{i, t-\tau}\right)+\sigma_{3}\left(I C I C_{i, t}-I C I C_{i, t-\tau}\right)+ \\
& \sum_{h=1}^{5} \delta_{h}\left(W_{h, i, t-\tau}-W_{h, i, t-2 \tau}\right)+\left(\vartheta_{i, t}-\vartheta_{i, t}-\tau\right) \\
& \vartheta_{i t}=\mathfrak{S}+\varepsilon_{t}-\varepsilon_{i, t}(3) \\
& \vartheta_{i t}+\vartheta_{i t}=\left(\varepsilon_{t}-\varepsilon_{t-\tau}\right)+\left(\varepsilon_{i, t}+\varepsilon_{i, t-\tau}\right)
\end{aligned}
$$

Where, $\mathrm{CO}_{\mathrm{I}, \mathrm{t}}$ is "a CO2 emissions indicator of country i at period $t$ "; $\sigma_{0}$ is a constant, IC represents ICT readiness, use, and intensity ( ICT access in basic services mobile phone penetration and internet penetration); ICIC is the quadratic interaction of ICT variables between identical ICT variables (e.g. "ICTBASIC × ICTBASIC"; "MOBILE PHONES × MOBILE PHONES" or "INTERNET × INTERNET"); W represents the vector of control variables namely: trade, GDP growth, population growth, education system quality, and regulation quality; $\tau$ represents the coefficient of auto-regression, which is one for the specification, because of limited degrees of freedom; $\xi_{t}$ is the time-specific constant; $\eta_{i}$ is the country-specific effects (or factors that are particular to each country in the sample), $\mathrm{u}_{\mathrm{i}}$, $\mathrm{t}$ is the two-way the disturbance term and $\varepsilon_{\mathrm{i}}, \mathrm{t}$ is the error term. 
The GMM empirical estimation adopted within the framework of this analysis is based on Roodman (2009a) which is an extension of the difference GMM methodology of Arellano and Bover (1995). The adopted process of estimation is the two-step estimator which is more robust when compared to the one-step process that exclusively accounts for homoscedasticity, compared to the two-step estimator that is heteroskedasticity-consistent. Similarly, to the current empirical literature, we employ all the explanatory variables as predetermined or suspected endogenous and exclusively acknowledge the time-invariant variables to display strict exogeneity (Asongu \& Le Roux, 2017; Asongu et al., 2018). Hence, Roodman (2009b) has confirmed that time-invariant variables cannot be endogenous after a first difference. The empirical literature has employed the Difference in Hansen Test (DHT) for the exogeneity of instruments to assess the validity of the exclusion restriction hypothesis. Additionally, for this assumption to hold, the null hypothesis of the underlying test should not be rejected (Tchamyou et al., 2019b).

Table 3: Correlation matrix

\begin{tabular}{|c|c|c|c|c|c|c|c|c|c|c|c|}
\hline Variable & ICTBASIC & МOB & INTER & CO2EM & Foss & METH & TRAD & GROW & POP & QES & $\mathrm{RQ}$ \\
\hline ICTBASIC & 1 & & & & & & & & & & \\
\hline МОВ & -0.0655 & 1 & & & & & & & & & \\
\hline INTER & 0.1034 & 0.6397 & 1 & & & & & & & & \\
\hline CO2EM & 0.009 & 0.4247 & 0.5311 & 1 & & & & & & & \\
\hline FOSS & -0.0599 & 0.2674 & 0.3876 & 0.545 & 1 & & & & & & \\
\hline METH & -0.0118 & -0.0627 & -0.0236 & 0.1509 & 0.0617 & 1 & & & & & \\
\hline TRAD & 0.5185 & 0.0262 & 0.0332 & -0.0132 & 0.0217 & 0.071 & 1 & & & & \\
\hline GROW & -0.0056 & 0.0136 & -0.0147 & -0.0012 & 0.0386 & -0.0302 & 0.0319 & 1 & & & \\
\hline POP & 0.0144 & -0.4603 & -0.4041 & -0.3284 & -0.1698 & -0.125 & 0.1751 & 0.0585 & 1 & & \\
\hline QES & 0.0269 & 0.49 & 0.3426 & 0.0829 & -0.076 & -0.2068 & -0.0986 & 0.0248 & -0.276 & 1 & \\
\hline $\mathrm{RQ}$ & 0.0729 & 0.4939 & 0.4425 & 0.1526 & 0.1866 & -0.1068 & 0.0212 & -0.0045 & -0.1468 & 0.3251 & 1 \\
\hline
\end{tabular}

Notes: CO2EM= CO2 emissions , FOSS= Fossil fuel energy consumption, METH= Methane emissions, INTER = Internet penetration, MOB= Mobile phone penetration, ICTBASIC $=$ Impact of ICTs on access to basic services, TRAD = Trade openess, GROW = GDP growth, POP= Population growth , QES= Quality of education system, RQ= Regulation quality.

\section{Empirical Results And Discussion}

The empirical findings are disclosed in Tables 4-6. Table 4 presents results about linkages between 'ICT access in basic services', 'internet penetration', 'mobile phone', and air pollution measured by 'CEO 2 emissions', 'fossil fuel energy consumption', 'methane emissions', Table 5 focuses on nexuses between ICT access in basic services', 'internet penetration', 'mobile phone' and 'fossil fuel energy consumption', while Table 6 is concerned with nexuses between ICT access in basic services', 'internet penetration', 'mobile phone', and air pollution measured by 'methane emissions'. Following GMM-centric literature, four criteria of information are assessed to verify the validity of results. In this section, net effects are calculated to check the overall consequence of growing ICT adoption on environmental sustainability. Regarding results in the fifth column of Table 4, the net effect of increasing mobile phone penetration is attaining $1.778([-0.0001 \times 73.44]+[0.016])$. Additionally, findings reported that the mean value of mobile phone penetration is 73.44 ; the unconditional effect of mobile phone penetration is 0.016 , while the marginal effect of increasing mobile phones is -0.0001 . These findings are in line with the current debate about the linkage between ICT and environmental indicators (Asongu. \& le Roux, 2017). Furthermore, in the fifth column of Table 5, the net effect from intensified internet penetration is $0.5466([-0.014 \times 15.88]+[0.127])$. Also, estimations revealed that the mean value of internet penetration is 15.88 ; the unconditional effect of internet penetration is 0.127 , while the marginal effect from intensifying internet penetration is -0.014 . 
According to the non-interactive regressions, results confirm that ICT readiness, use, and intensity (i.e. ICT access in basic services and mobile phones) significantly affects $\mathrm{CO} 2$ emissions, and only internet penetration doses did not affect the $\mathrm{CO} 2$ emission. Furthermore, concerning the interactive regressions, intensifying ICT readiness and use (Mobile phone and internet penetration) has a positive net effect on per capita $\mathrm{CO} 2$ emissions, whereas developing ICT access in basic services reported a negative net effect on $\mathrm{CO} 2$ emissions from liquid fuel consumption (Avom el al., 2020). The estimations values presented in Tables 4-6, provide evidence that most of the significant control variables have signs as anticipated and detailed in the literature review section.

Our findings suggest that increasing ICT access in basic services is positively and significantly associated with $\mathrm{CO} 2$ emissions per capita. The corresponding marginal effect was negative. This negative marginal effect implies that at a determined threshold of ICT access in basic services, the net impact can be transformed from positive to negative. Therefore, thresholds must be within the range of corresponding data to present economic sense and policy significance. Thus, firstly we present more clarification about the definition of the threshold, secondly, we calculate their values related to the net positive effects. Authors and scholars reported that threshold can be defined as a value at which, additional ICT diffusion established a net negative effect on CO2 per capita emissions. For this reason, to exactly determine the threshold point of the environmental sustainability indicators, we should compare these values with the minimum and maximum values reported in the descriptive statistics. Even though, the policymakers needed to intensify both the ICT readiness, use, and intensity further than the recognized thresholds. As we have noted, this conception of the threshold is similar to the current literature.

According to Table 4, the mentioned values are the minimum required thresholds of ICT use and readiness able to decrease $\mathrm{CO} 2$ emissions. Firstly, the threshold for ICT access in basic services is $0.01576(0.00082 / 0.052)$. Secondly, the threshold for mobile phone penetration per 100 people is $160(0.016 / 0.0001)$. Thirdly, the threshold for internet penetration per 100 people is 46.58 $(0.0559 / 0.0012)$. Hence, the mobile penetration range is between 0.000 and 175.30 per 100 people and internet penetration also ranges between 0.000 and 56.8, only the computed threshold of ICT access in basic services can make economic sense or policy relevance (range between 1.92 and 6.33). It follows that decreasing the impact of ICT access in basic services rate to above 0.01576, would moderate $\mathrm{CO} 2$ per capita emissions and boost environmental sustainability. Similarly, in Table 5 we report findings as follows: The threshold value of ICT penetration able to decrease fossil fuel energy consumption are: Firstly, 10.35 (5.736/0.554) is the threshold value for the impact of ICT access in basic services. Secondly, the threshold value for mobile phone penetration per 100 people is equal to $244.28(0.171 / 0.0007)$. Thirdly, the threshold value is $54.92(0.769 / 0.014)$ for internet penetration per 100 people. To sum up the findings, the mobile penetration, mobile phone, and ICT access in basic services range beyond the threshold's values computed in Table 5, it is necessary to increase the impact of ICT readiness and use to moderate the fossil fuel energy consumption. In consequence, the intended thresholds values of ICT readiness and use are the minimum levels to achieve the objective of a sustainable environment through increasing fossil fuel energy consumption in the lower and lower-middleincome countries.

Policymakers should have been given more effort on this topic and focused more on developing the technology sector. They should investigate in many the differents matters linked to ICT readiness, use and intensity like internet accessibility in the basic services, and ICT infrastructure in the poorer countries, and especially, the rural regions. Moreover, to improve financial access government should invest in their ICT infrastructure by developing low pricing and broad coverage internet (Añon Higon et al., 2017; Zhang et al., 2019; Murshed, 2020). Therefore, governments in the lower and lower-middle-income countries necessitate to take on a series of environmental policy to concentrate on environmental challenges. Generally, government laws have a strong connection with the overall regional ecological performance; that is, strict regulatory regulation might guide firms and businesses to transform their production system and advance regional ecological efficiency by implementing the smart system in their organizations. Moreover, this paper is in line with the recommendations of the Paris Agreement. This research joins these current debates and puts forward the following proposals for developing the role played by technological innovation on promoting environmental sustainability in the lower-income countries. Under the Paris Agreement, World leaders adopted the 2030 Agenda for Sustainable Development. Finally, these international actions can guide countries to promote the environmental dimension of sustainable development and leads to socio-economic development by reducing environmental risks and increasing the resilience of societies and the environment as an entire. 
GMM estimations for ICT and CO2 emissions

\begin{tabular}{|c|c|c|c|c|c|c|}
\hline \multicolumn{7}{|l|}{ Panel 1: CO2 emissions } \\
\hline & \multicolumn{2}{|c|}{$\begin{array}{l}\text { ICT ACCESS IN BASIC } \\
\text { SERVICES }\end{array}$} & \multicolumn{2}{|c|}{ MOBILE PHONE } & \multicolumn{2}{|c|}{ INTERNET PENETRATION } \\
\hline \multirow[t]{2}{*}{ Constant } & 0.6728 & -0.184 & 0.25 & 0.3264 & 0.339 & 0.2408 \\
\hline & 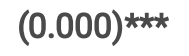 & $(0.021) * \star$ & $(0.000) * * *$ & $(0.000) * \star *$ &  & $(0.000) * \star \star$ \\
\hline \multirow[t]{2}{*}{ COE E(-1) } & 0.6252 & 0.633 & 0.729 & 0.7633 & 0.739 & 0.7910 \\
\hline & $(0.000)^{\star \star \star}$ & $(0.000) * \star *$ & $(0.000) * \star \star$ & $(0.000) * \star \star$ & $(0.000) * * *$ & $(0.000) * * *$ \\
\hline \multirow[t]{2}{*}{ ICTB } & -0.0304 & 0.00082 & - & - & - & - \\
\hline & $(0.000) * *$ & $(0.012) * \star$ & & & & \\
\hline \multirow[t]{2}{*}{ ICTB $^{2}$} & - & -0.052 & - & - & - & - \\
\hline & & $(0.000) * *$ & & & & \\
\hline \multirow[t]{2}{*}{ MOBILE PHONE } & - & - & 0.0028 & 0.016 & - & - \\
\hline & & & $(0.000) * * *$ & $(0.000) * * *$ & & \\
\hline \multirow[t]{2}{*}{ MOBILE PHONE² } & & & - & -0.0001 & - & - \\
\hline & & & & $(0.000) * * *$ & & \\
\hline \multirow[t]{2}{*}{ INTERNET PENETRATION } & - & - & - & - & 0.0001 & 0.0559 \\
\hline & & & & & $(0.412)$ & $(0.000) * \star \star$ \\
\hline \multirow[t]{2}{*}{ INTERNET PENETRATION² } & - & - & - & - & - & -0.0012 \\
\hline & & & & & & $(0.000) \star \star \star$ \\
\hline \multirow[t]{2}{*}{ TRADE OPENESS } & -0.005 & 0.023 & -0.14 & -0.174 & -0.034 & -0.0744 \\
\hline & $(0.037) * \star$ & $(0.000) * * *$ & $(0.000) * \star \star$ & $(0.000) * \star *$ & $(0.000) * \star \star$ & 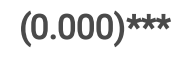 \\
\hline \multirow[t]{2}{*}{ GROWTH } & -0.002 & -0.0004 & -0.0045 & -0.0006 & -0.0015 & -0.0050 \\
\hline & 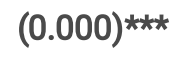 & $(0.037)$ * & $(0.000) * * *$ & $(0.049) * *$ & 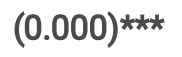 &  \\
\hline \multirow[t]{2}{*}{ POP GROWTH } & -.004 & -0.0007 & 0.0114 & 0.0103 & 0.0068 & 0.0197 \\
\hline &  & $(0.140)$ & $(0.000) * * *$ & $(0.000) * * *$ &  & $(0.000) * \star \star$ \\
\hline \multirow{2}{*}{$\begin{array}{l}\text { EDUCATION SYSTEM } \\
\text { QUALITY }\end{array}$} & -0.038 & -0.049 & -0.042 & -0.1607 & -0.0152 & -0.092 \\
\hline & $(0.000) * \star \star$ & $(0.000) * \star *$ & $(0.000) * * *$ & $(0.000) * \star \star$ & $(0.000) * \star \star$ & 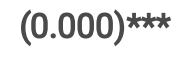 \\
\hline \multirow[t]{2}{*}{ REGULATION QUALITY } & 0.114 & 0.184 & 0.0255 & 0.206 & 0.114 & 0.2308 \\
\hline & $(0.000) * \star \star$ &  & $(0.171)$ &  & $(0.000) * \star \star$ &  \\
\hline Time effects & Yes & Yes & Yes & Yes & Yes & Yes \\
\hline $\operatorname{AR}(1)$ & 0.085 & 0.087 & 0.052 & 0.067 & 0.078 & 0.095 \\
\hline $\operatorname{AR}(2)$ & 0.666 & 0.761 & 0.574 & 0.113 & 0.356 & 0.299 \\
\hline \multicolumn{7}{|c|}{$\begin{array}{l}\text { Note: } * * \star, * *, *: \text { "Significance levels at } 1 \%, 5 \% \text { and } 10 \% \text { respectively. DHT: Difference in Hansen Test for Exogeneity of } \\
\text { Instruments Subsets. Dif: Difference. OIR: Overidentifying Restrictions Test. The significance of bold values is twofold. 1) The } \\
\text { significance of estimated coefficients and the Fisher statistics. 2) The failure to reject the null hypotheses of a) no } \\
\text { autocorrelation in the AR(1) \& AR(2) tests and; b) the validity of the instruments in the Sargan and Hansen OIR tests. Constants } \\
\text { are included in all regressions. n.a: not applicable because at least one estimated coefficient needed for the computation of } \\
\text { thresholds is not significant. nsa: not specifically applicable either because the model is invalid or the corresponding thresholds } \\
\text { have unexpected signs". }\end{array}$} \\
\hline
\end{tabular}




\begin{tabular}{|c|c|c|c|c|c|c|}
\hline \multicolumn{7}{|l|}{ Panel 1: CO2 emissions } \\
\hline Net effects & nsa & -0.2419 & nsa & 1.1778 & nsa & 0.8880 \\
\hline Sargan OIR & 0.003 & 0.003 & 0.006 & 0.008 & 0.004 & 0.003 \\
\hline Hansen OIR & 0.852 & 0.816 & 0.733 & 0.554 & 0.747 & 0.345 \\
\hline \multicolumn{7}{|l|}{ DHT for instruments } \\
\hline \multirow{2}{*}{$\begin{array}{l}\text { (a)GMM instruments for } \\
\text { levels }\end{array}$} & 0.228 & 0.333 & 0.393 & 0.370 & 0.304 & 0.222 \\
\hline & \multicolumn{2}{|c|}{ H excluding group } & 0.410 & 0.654 & 0.312 & 0.350 \\
\hline \multicolumn{7}{|l|}{ DIF (null, $\mathrm{H}=$ exogenous) } \\
\hline \multicolumn{7}{|l|}{ (b)IV(year, eq(diff)) } \\
\hline \multicolumn{7}{|l|}{ H excluding group } \\
\hline \multicolumn{7}{|l|}{ Dif(null, $\mathrm{H}=$ exogenous) } \\
\hline & 0.756 & 0.838 & 0.393 & 0.540 & 0.642 & 0.732 \\
\hline & 0.278 & 0.119 & 0.564 & 0.764 & 0.499 & 0.255 \\
\hline Fisher & $5505.15^{\star \star \star}$ & $4685.11^{\star \star \star}$ & $19491.58 * \star *$ & $8888.72^{\star \star *}$ & $25048.59 * * *$ & $4408.93^{* \star *}$ \\
\hline Instruments & 27 & 27 & 27 & 27 & 27 & 27 \\
\hline Observations & 228 & 228 & 228 & 228 & 228 & 228 \\
\hline \multicolumn{7}{|c|}{$\begin{array}{l}\text { Note: } * * *, * * * \text { : "Significance levels at } 1 \%, 5 \% \text { and } 10 \% \text { respectively. DHT: Difference in Hansen Test for Exogeneity of } \\
\text { Instruments Subsets. Dif: Difference. OIR: Overidentifying Restrictions Test. The significance of bold values is twofold. 1) The } \\
\text { significance of estimated coefficients and the Fisher statistics. } 2 \text { ) The failure to reject the null hypotheses of a) no } \\
\text { autocorrelation in the AR(1) \& AR(2) tests and; b) the validity of the instruments in the Sargan and Hansen OIR tests. Constants } \\
\text { are included in all regressions. n.a: not applicable because at least one estimated coefficient needed for the computation of } \\
\text { thresholds is not significant. nsa: not specifically applicable either because the model is invalid or the corresponding thresholds } \\
\text { have unexpected signs". }\end{array}$} \\
\hline
\end{tabular}


GMM estimations for ICT and fossil fuel energy consumption

Panel 2: Fossil fuel energy consumption

\begin{tabular}{|c|c|c|c|c|c|c|}
\hline \multirow[b]{2}{*}{ Constant } & \multicolumn{2}{|c|}{ ICT ACCESS IN BASIC SERVICES } & \multicolumn{2}{|c|}{ MOBILE PHONE } & \multicolumn{2}{|c|}{ INTERNET PENETRATION } \\
\hline & 25.22 & 34.54 & 16.165 & 16.85 & 18.85 & 19.22 \\
\hline & $(0.000) * \star \star$ & $(0.000) * \star *$ & $(0.000) * * *$ & $(0.000) * * *$ & 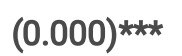 & $(0.000) * * *$ \\
\hline \multirow[t]{2}{*}{ FOSSIL(-1) } & 0.6239 & 0.631 & 0.658 & 0.672 & 0.565 & 0.551 \\
\hline & $(0.000) * * *$ & $(0.000) * * *$ & $(0.000) * * *$ & 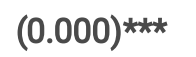 & $(0.000) * \star \star$ & $(0.000) * * *$ \\
\hline \multirow[t]{2}{*}{ ICTB } & -1.077 & -5.736 & - & - & - & - \\
\hline & $(0.000) * \star *$ & $(0.000) * * *$ & & & & \\
\hline \multirow[t]{2}{*}{ ICTB $^{2}$} & - & 0.554 & - & - & - & - \\
\hline & & $(0.000) * * *$ & & & & \\
\hline \multirow[t]{2}{*}{ MOBILE PHONE } & - & - & 0.048 & 0.171 & - & - \\
\hline & & & $(0.000) * \star *$ & 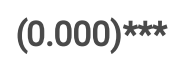 & & \\
\hline \multirow[t]{2}{*}{ MOBILE PHONE ${ }^{2}$} & & - & - & -0.0007 & - & - \\
\hline & & & & 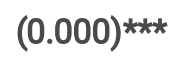 & & \\
\hline \multirow[t]{2}{*}{ INTERNET PENETRATION } & - & - & - & - & 0.127 & 0.769 \\
\hline & & & & & $(0.000) * \star *$ & $(0.000) * * *$ \\
\hline \multirow[t]{2}{*}{ INTERNET PENETRATION² } & - & - & - & - & - & -0.014 \\
\hline & & & & & & $(0.000)^{\star \star \star}$ \\
\hline \multirow[t]{2}{*}{ TRADE OPENESS } & 1.70 & 1.491 & 0.331 & 0.240 & 1.985 & 2.09 \\
\hline & $(0.000) * * *$ & $(0.000) * * *$ & $(0.226)$ & 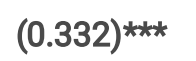 & $(0.000) * * *$ & $(0.000) * * *$ \\
\hline \multirow[t]{2}{*}{ GROWTH } & 0.148 & 0.167 & 0.105 & 0.129 & 0.178 & 0.128 \\
\hline & $(0.000) * \star *$ & $(0.000) * * *$ & $(0.000) * * *$ & $(0.000) * \star \star$ & $(0.000) * \star *$ & 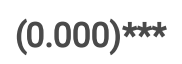 \\
\hline \multirow[t]{2}{*}{ POP GROWTH } & -0.236 & -0.356 & -0.040 & -0.064 & -0.116 & -0.019 \\
\hline & $(0.000) * * *$ & $(0.000) * \star *$ & $(0.331)$ & $(0.195)$ & $(0.000) * * *$ & $(0.283)$ \\
\hline \multirow[t]{2}{*}{ EDUCATION SYSTEM QUALITY } & -0.499 & -0.363 & -0.789 & -1.955 & -0.465 & -1.381 \\
\hline & 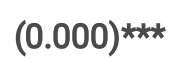 & $(0.000) * \star *$ & $(0.000) * * *$ & 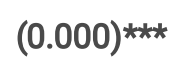 & $(0.000) \star \star \star$ & $(0.000)^{\star \star *}$ \\
\hline \multirow[t]{2}{*}{ REGULATION QUALITY } & 0.765 & 0.858 & -0.434 & 1.69 & -2.42 & -1.061 \\
\hline & $(0.465)$ & $(0.000) * \star *$ & $(0.503)$ & 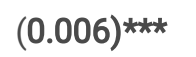 & 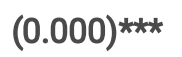 & $(0.097) *$ \\
\hline Time effects & Yes & Yes & Yes & Yes & Yes & Yes \\
\hline Net effects & nsa & -3.4825 & nsa & 0.1195 & nsa & 0.5466 \\
\hline $\operatorname{AR}(1)$ & 0.043 & 0.040 & 0.050 & 0.043 & 0.049 & 0.038 \\
\hline
\end{tabular}

Note: $* \star \star, \star \star, *:$ "Significance levels at $1 \%, 5 \%$ and $10 \%$ respectively. DHT: Difference in Hansen Test for Exogeneity of Instruments Subsets. Dif: Difference. OIR: Overidentifying Restrictions Test. The significance of bold values is twofold. 1) The significance of estimated coefficients and the Fisher statistics. 2) The failure to reject the null hypotheses of a) no autocorrelation in the $A R(1)$ \& $A R(2)$ tests and; $b$ ) the validity of the instruments in the Sargan and Hansen OIR tests. Constants are included in all regressions. n.a: not applicable because at least one estimated coefficient needed for the computation of thresholds is not significant. nsa: not specifically applicable either because the model is invalid or the corresponding thresholds have unexpected signs." 


\begin{tabular}{|c|c|c|c|c|c|c|}
\hline \multicolumn{7}{|c|}{ Panel 2: Fossil fuel energy consumption } \\
\hline $\operatorname{AR}(2)$ & 0.457 & 0.453 & 0.493 & 0.439 & 0.459 & 0.322 \\
\hline Sargan OIR & 0.003 & 0.002 & 0.014 & 0.013 & 0.003 & 0.012 \\
\hline Hansen OIR & 0.694 & 0.695 & 0.699 & 0.798 & 0.566 & 0.496 \\
\hline \multicolumn{7}{|l|}{ DHT for instruments } \\
\hline (a)GMM instruments for levels & 0.657 & 0.587 & 0.376 & 0.370 & 0.434 & 0.421 \\
\hline H excluding group & 0.376 & 0.278 & 0.255 & 0.243 & 0.687 & 0.764 \\
\hline \multicolumn{7}{|l|}{ DIF (null, $\mathrm{H}=$ exogenous) } \\
\hline \multicolumn{7}{|l|}{ (b)IV(year, eq(diff)) } \\
\hline \multicolumn{7}{|l|}{ H excluding group } \\
\hline \multicolumn{7}{|l|}{ Dif(null, $\mathrm{H}=$ exogenous) } \\
\hline & 0.691 & 0.688 & 0.899 & 0.598 & 0.461 & 0.798 \\
\hline & 0.278 & 0.2543 & 0.561 & 0.322 & 0.605 & 0.116 \\
\hline Fisher & $3963.92 * \star *$ & $1597.27 * \star *$ & $3608.27 * \star *$ & $2305.82 * \star *$ & $1453.97 * * *$ & $4763.78 * * *$ \\
\hline Instruments & 27 & 27 & 27 & 27 & 27 & 27 \\
\hline Observations & 228 & 228 & 228 & 228 & 228 & 228 \\
\hline \multicolumn{7}{|c|}{$\begin{array}{l}\text { Note: } * * *, * *, *: \text { "Significance levels at } 1 \%, 5 \% \text { and } 10 \% \text { respectively. DHT: Difference in Hansen Test for Exogeneity of } \\
\text { Instruments Subsets. Dif: Difference. OIR: Overidentifying Restrictions Test. The significance of bold values is twofold. 1) The } \\
\text { significance of estimated coefficients and the Fisher statistics. 2) The failure to reject the null hypotheses of a) no } \\
\text { autocorrelation in the AR(1) \& AR(2) tests and; b) the validity of the instruments in the Sargan and Hansen OIR tests. Constants } \\
\text { are included in all regressions. n.a: not applicable because at least one estimated coefficient needed for the computation of } \\
\text { thresholds is not significant. nsa: not specifically applicable either because the model is invalid or the corresponding thresholds } \\
\text { have unexpected signs." }\end{array}$} \\
\hline
\end{tabular}


GMM estimations for ICT and methane emissions

\begin{tabular}{|c|c|c|c|c|c|c|}
\hline \multicolumn{7}{|c|}{ Panel 2: Methane emissions } \\
\hline \multirow{3}{*}{ Constant } & \multicolumn{2}{|c|}{ ICT ACCESS IN BASIC SERVICES } & \multicolumn{2}{|c|}{ MOBILE PHONE } & \multicolumn{2}{|c|}{ INTERNET PENETRATION } \\
\hline & \multirow{2}{*}{$\begin{array}{l}0.88142 \\
(0.000) \star \star \star\end{array}$} & 0.8912 & 0.7591 & 0.7758 & \multirow{2}{*}{$\begin{array}{l}.7814256 \\
(0.000) * * *\end{array}$} & 0.7875 \\
\hline & & $(0.000) * \star *$ & $(0.000) * \star \star$ & $(0.000) * * *$ & & $(0.000) * * *$ \\
\hline \multirow[t]{2}{*}{ METHANE(-1) } & 0.33979 & 0.3424 & 0.3644 & 0.3582 & \multirow{2}{*}{$\begin{array}{l}.3557432 \\
(0.000) * * \star\end{array}$} & 0.3561 \\
\hline & $(0.000) * * *$ & $(0.000) * \star \star$ & $(0.000)^{\star \star *}$ & $(0.000) * \star *$ & & $(0.000) * * *$ \\
\hline \multirow[t]{2}{*}{ ICTB } & \multirow{2}{*}{$\begin{array}{l}-.034440 \\
(0.000) * \star \star\end{array}$} & -0.371 & \multirow[t]{2}{*}{-} & \multirow[t]{2}{*}{-} & \multirow[t]{2}{*}{-} & \multirow[t]{2}{*}{-} \\
\hline & & $(0.005) * * *$ & & & & \\
\hline \multirow[t]{2}{*}{ ICTB $^{2}$} & \multirow[t]{2}{*}{-} & 0.00046 & \multirow[t]{2}{*}{-} & \multirow[t]{2}{*}{-} & \multirow[t]{2}{*}{-} & \multirow[t]{2}{*}{-} \\
\hline & & $(0.763)$ & & & & \\
\hline \multirow[t]{2}{*}{ MOBILE PHONE } & \multirow[t]{2}{*}{-} & \multirow[t]{2}{*}{-} & 0.00041 & 0.0030 & \multirow[t]{2}{*}{-} & \multirow[t]{2}{*}{-} \\
\hline & & & $(0.000) * \star \star$ & 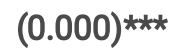 & & \\
\hline \multirow[t]{2}{*}{ MOBILE PHONE ${ }^{2}$} & \multirow[t]{2}{*}{-} & \multirow[t]{2}{*}{-} & \multirow[t]{2}{*}{-} & -0.00001 & - & - \\
\hline & & & & $(0.000)^{\star \star *}$ & & \\
\hline $\begin{array}{l}\text { INTERNET } \\
\text { PFNFTRATION }\end{array}$ & - & - & - & - & -.0009612 & -0.0030 \\
\hline & & & & & & $(0.000) * * *$ \\
\hline INTERNET & - & - & - & - & - & 0.00004 \\
\hline PENETRATION² & & & & & & $(0.000)^{\star \star *}$ \\
\hline TRADE OPENESS & 0.08565 & 0.0839 & 0.04613 & 0.0490 & .0510464 & 0.05132 \\
\hline & $(0.000) * * *$ & $(0.000) * \star *$ & $(0.000) * \star *$ & $(0.000) * * *$ & & $(0.000) * * *$ \\
\hline GROWTH & 0.00166 & 0.0018 & 0.0014 & 0.0020 & .0010766 & 0.0012 \\
\hline & & $(0.000) * * *$ & $(0.000)^{\star \star \star}$ & $(0.000)^{\star \star \star}$ & & $(0.000)^{\star \star \star}$ \\
\hline POP GROWTH & -0.00832 & -0.0083 & -0.0069 & -0.0074 & -.0090498 & -0.0092 \\
\hline & $(0.000) * \star *$ & 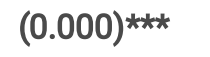 & $(0.000) * \star \star$ & 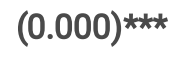 & & $(0.000)$ \\
\hline EDUCATION SYSTEM & -0.05404 & -0.05523 & -0.0651 & -0.0861 & -.0498051 & -0.0474 \\
\hline & . & $(0.000) * * *$ & $(0.000) * \star \star$ & $(0.000) * \star *$ & & $(0.000) * * *$ \\
\hline REGULATION QUALITY & $-0.00961(0.315)$ & -0.0083 & 0.0008 & 0.0388 & 0.01062 & 0.0132 \\
\hline & & $(0.420) * \star *$ & $(0.939)$ & $(0.000) * \star *$ & & $(0.076) *$ \\
\hline Time effects & Yes & Yes & Yes & Yes & Yes & Yes \\
\hline Net effects & Nsa & -0.3691 & nsa & 0.0022 & nsa & -0.0023 \\
\hline $\operatorname{AR}(1)$ & 0.000 & 0.000 & 0.000 & 0.000 & 0.000 & 0.000 \\
\hline
\end{tabular}

Note: ***,**,*: "Significance levels at 1\%,5\% and 10\% respectively. DHT: Difference in Hansen Test for Exogeneity of Instruments Subsets. Dif: Difference. OIR: Overidentifying Restrictions Test. The significance of bold values is twofold. 1) The significance of estimated coefficients and the Fisher statistics. 2) The failure to reject the null hypotheses of a) no autocorrelation in the AR(1) \& AR(2) tests and; b) the validity of the instruments in the Sargan and Hansen OIR tests. Constants are included in all regressions. n.a: not applicable because at least one estimated coefficient needed for the computation of thresholds is not significant. nsa: not specifically applicable either because the model is invalid or the corresponding thresholds have unexpected signs." 


\begin{tabular}{|c|c|c|c|c|c|c|}
\hline \multicolumn{7}{|c|}{ Panel 2: Methane emissions } \\
\hline $\operatorname{AR}(2)$ & 0.082 & 0.091 & 0.255 & 0.120 & 0.292 & 0.283 \\
\hline Sargan OIR & 0.998 & 0.997 & 0.322 & 0.997 & 0.942 & 0.997 \\
\hline Hansen OIR & 0.983 & 0.990 & 1 & 0.965 & 0.966 & 0.915 \\
\hline \multicolumn{7}{|l|}{ DHT for instruments } \\
\hline \multirow{2}{*}{$\begin{array}{l}\text { (a)GMM instruments for } \\
\text { levels } \\
\text { H excluding group }\end{array}$} & 0.672 & 0.616 & 0.322 & 0.376 & 0.332 & 0.286 \\
\hline & 0.376 & 0.312 & 0.112 & 0.321 & 0.235 & 0.175 \\
\hline \multicolumn{7}{|l|}{ DIF (null, $\mathrm{H}=$ exogenous) } \\
\hline \multicolumn{7}{|l|}{ (b)IV(year, eq(diff)) } \\
\hline \multicolumn{7}{|l|}{ H excluding group } \\
\hline \multicolumn{7}{|l|}{ Dif(null, $\mathrm{H}$ = exogenous) } \\
\hline & 0.693 & 0.490 & 0.259 & 0.758 & 0.450 & 0.696 \\
\hline & 0.554 & 0.344 & 0.376 & 0.892 & 0.213 & 0.116 \\
\hline Fisher & $23690.74 * * *$ & $18378.47 * \star \star$ & $31439.09 * * *$ &  & $16324.32 * \star *$ & $39299.93 * \star *$ \\
\hline Instruments & 27 & 27 & 27 & 27 & 27 & 27 \\
\hline Observations & 228 & 228 & 228 & 228 & 228 & 228 \\
\hline \multicolumn{7}{|c|}{$\begin{array}{l}\text { Note: } * * *, * *, *: \text { "Significance levels at } 1 \%, 5 \% \text { and } 10 \% \text { respectively. DHT: Difference in Hansen Test for Exogeneity of } \\
\text { Instruments Subsets. Dif: Difference. OIR: Overidentifying Restrictions Test. The significance of bold values is twofold. 1) The } \\
\text { significance of estimated coefficients and the Fisher statistics. 2) The failure to reject the null hypotheses of a) no } \\
\text { autocorrelation in the AR(1) \& AR(2) tests and; b) the validity of the instruments in the Sargan and Hansen OIR tests. Constants } \\
\text { are included in all regressions. n.a: not applicable because at least one estimated coefficient needed for the computation of } \\
\text { thresholds is not significant. nsa: not specifically applicable either because the model is invalid or the corresponding thresholds } \\
\text { have unexpected signs." }\end{array}$} \\
\hline
\end{tabular}

\section{Conclusion And Policy Implications}

This paper aims to study how increasing ICT readiness, use, and intensity in the lower and lower-middle-income countries can contribute to achieving an SDG such as environmental sustainability by reducing $\mathrm{CO} 2$ and methane emissions. This study suggested empirical evidence based on the Generalized Method of Moments estimations and fifty-seven countries over the period 2012-2016. ICT is measured with the impact of ICT on access to basic services, phone penetration, and internet penetration, while CO2 emissions per capita, fossil fuel energy consumption, and methane emissions are used as indicators for air pollution. To sum up the findings, the non-interactive regressions confirm that increasing ICT readiness and use (i.e. mobile phones and the internet) significantly influence $\mathrm{CO} 2$, fossil fuel energy consumption, and methane emissions. Taken together, we conclude that increasing ICT has a positive net effect on $\mathrm{CO} 2$ and methane emissions per capita while increasing the impact of ICT access in basic services has a net negative effect on $\mathrm{CO} 2$, fossil fuel energy consumption, and methane emissions. To explore this issue further, the negative net effects suggest that ICT needs to be further developed beyond the determined thresholds, to attain the required negative net effect on fossil fuel energy consumption. We have determined these required threshold values and found them to be respectively: 244.28 per 100 people for mobile phone penetration and 10.35 for the impact of ICT access in basic services. While the former is not within practical range only for internet penetration and thus has no practical implication for policy, the latter is within achievable range (56.80) and is of policy relevance. As we have noted that an internet penetration range of above 54.92 for every 100 people helps to create a sustainable environment through moderating $\mathrm{CO} 2$ and fossil fuel energy consumption. The fact that the threshold at which this is possible exclusively make economic sense for mobile phone and ICT in basic services is interesting because the internet can be used on many devices, such as the mobile phone. Even though, intensifying ICT access in basic services is unthinkingly more pertinent than the mobile phone, though both are also complementary. 
Policy implications can be drawn from this study. Firstly, developing countries should continue investing in the promotion of their ICT infrastructure to enhance their ICT readiness and intensify the use of new technologies to be able to monitor air pollution.

Besides, GHG is a serious barrier related to sustainable economic development. The world needs immediate emissions reduction to avoid the long-term danger of climate change. Secondly, government authorities should give additional efforts in the more pollutant sector such as transport and industry to monitor their energy consumption. All the government authorities propose many policies to limit GHG emissions and other short-lived climate pollutants. These initiatives contribute to the establishment of inclusive development, health, and other social advantages. They show that countries can save electricity and fuel by implementing the smart city project. These measures could also diminish the health problem as a result of air pollution. Thirdly, decision-makers should motivate the exchange of goods that allow the digital transformation of the production processes. Besides, to decrease the energy consumption resulting in the transport of goods, policymakers should promote the consumption of renewable energy by developing the financial sector to finance renewable energy projects. Also, smart technologies can help in reducing traffic congestion which contributes to economic development and enhance health quality. Finally, it must be mentioned that, in developing and emerging economies, the challenge of the wider deployment of low-carbon technologies is still related to technology readiness and intensity. Furthermore, a lack of awareness of the benefits of ICT adoption is known as the main barrier to saving energy. People in the low and low-middle-income countries should be acknowledged of the potential impact of innovative solutions to a sustainable environment since ICT help in reducing emissions by building smart cities and digital production systems. Thus, a greater intention needs to be paid to control the high costs of new technologies, especially for smart grids and smart cities.

\section{Declarations}

\section{Data availability:}

Data available upon request

Funding: The authors declare that this study did not receive any funding from funding agencies and authors institutions.

\section{Author information:}

AMARI Mouna , Assistant Professor, LARTIGE laboratory, University of GABES, Tunisia, amarimouna86@gmail.com.

JARBOUI Anis, Full Professor, LARTIGE laboratory, University of business of Normandy, France, anis.jarboui01@em-normandie.fr .

Contributions: AMARI and JARBOUI searched and obtained all literatures used in this review. AMARI and JARBOUI wrote the manuscript draft, read, corrected and approved the final manuscript.

Corresponding author:AMARI Mouna , Assistant Professor, LARTIGE laboratory, University of GABES, Tunisia, correspondence to amarimouna86@gmail.com

Ethical approval: Not applicable

Consent to participate: Not applicable

Consent for publication: Not applicable

Competing Interest: The authors declare that they have no competing interests linked to this article.

Availability of data and materials: upon request.

\section{References}

1. Ahmed, K., \& Ozturk, I. (2018). What new technology means for the energy demand in China? A sustainable development perspective. Environmental Science and Pollution Research, 25(29).

2. Akinyemi, O. E. (2018). Green Growth Strategy and Trade Performance in sub-Saharan Africa. Department of Economics and Development Covenant University, Nigeria. 
3. Amari., M., Baklouti, N., \& Mouakhar, K. (2020). International comparative evidence of E-Government success and economic growth: Technology adoption as an anti-corruption tool. Transforming Government People Process and Policy, 1-20.

4. Amri, F. (2017). Carbon dioxide emissions, output, and energy consumption categories in Algeria. Environmental Science and Pollution Research volume, 24, 14567-14578.

5. Amri, F. (2018). Carbon dioxide emissions, total factor productivity, ICT, trade, financial development, and energy consumption: testing environmental Kuznets curve hypothesis for Tunisia. Environmental Science and Pollution Research, 25(3), 1-12.

6. Anyanwu, J., \& Erhijakpor, A. (2014). Does Oil Wealth Affect Democracy in Africa? African Development Review, 26(1), 15-37.

7. Arif, F. N. (2020). Information and communication technology (ICT) and environmental. Environmental Science and Pollution Research, 1-14.

8. Ashraf Q., G. O. (2013). The 'Out of Africa' hypothesis, human genetic diversity, and comparative economic development. American Economic Review, 103(1), 1-46.

9. Asongu, S. (2018). CO2 emission thresholds for inclusive human development in sub-Saharan Africa. Environmental Science and Pollution Research, 25(26), 26005-26019.

10. Asongu, S. (2020). The Effects of Mobile Phone Technology, Knowledge Creation and Diffusion on Inclusive Human Development in Sub-Saharan Africa. Journal of the Knowledge Economy, 1-15.

11. Asongu., S. A. (2013). Globalization and Africa: implications for human development. International Journal of Development Issues, 12(3), 213-238.

12. Asongu., S., \& le Roux, S. (2017). Enhancing ICT for environmental sustainability in sub-Saharan Africa. Technological Forecasting and Social Change, 209-216.

13. Asongu., S., El Montasser., G., \& Toumi., H. (2016). Testing the relationships between energy consumption, $\mathrm{CO} 2$ emissions, and economic growth in 24 African countries: a panel ARDL approach. Environmental Science and Pollution Research, 23, 65636573.

14. Atici, C. (2012). Carbon emissions, trade liberalization, and the Japan-ASEAN interaction: A group-wise examination. Journal of the Japanese and International Economies, 26, 167-178.

15. Avom., D., Hilaire, N., Kaffo, F. H., \& Armand, T. (2020). ICT and environmental quality in Sub-Saharan Africa: Effects and transmission channels. Technological Forecasting \& Social Change, 155, 120028.

16. Balsalobre, D. Á. (2015). Public budgets for energy RD\&D and the effects on energy intensity and pollution levels. Environmental Science and Pollution Research , 4881-4892.

17. Belloumi., M. (2009). Energy consumption and GDP in Tunisia: cointegration and causality. Energy Policy, 37(7), $2745-2753$.

18. Blundell, R. B. (1998). Initial conditions and moment restrictions in dynamic panel data. Journal of Econometrics, 87, 115-143.

19. Demena., B. A., \& Afesorgbor., S. (2020). The effect of FDI on environmental emissions: Evidence from a meta-analysis. Energy Policy, 138, 111192.

20. Hao, Y., \& Liu, Y. (2015). Has the development of FDI and foreign trade contributed to China's CO2 emissions? An empirical study with provincial panel data. Natural Hazards, 76, 1079-1091.

21. Higon DA, G. R. (2017). ICT and environmental sustainability: a global perspective. Telematics and Informatics, 4(34), 85-95.

22. Khurshid, A. H. (2019). Does information and communication technologies improve environmental quality in the era of globalization? An empirical analysis. Environmental Science and Pollution Research, 8594-8608.

23. Lahouel, F. A. (2019). ICT, total factor productivity, and carbon dioxide emissions in Tunisia. Technological Forecasting and Social Change, 146, 212-217.

24. Nicholas, A. S. (2017). Environmental degradation, ICT and Environmental degradation and inclusive development in SubSaharan Africa. Energy policy, 111, 353-361.

25. Omri., A., \& Tarek, B. (2020). Foreign investment and air pollution: Do good governance and technological innovation matter? . Environmental Research, doi.org/10.1016/j.envres.2020.109469.

26. Omri., A., Saida, D. \&., \& Chaibi, A. (2015). Financial development, environmental quality, trade and economic growth: What causes what in MENA countries. Energy Economics, 48, 242-252. 
27. Omri., Euchi, J., \& Hafiez, H. A.-T. (2019). Determinants of environmental sustainability: Evidence from Saudi Arabia. Science of The Total Environment, 657, 1592-1601.

28. Pénard., T., Nicolas, P., ZOMO, Y. G., \& Philémon, N. E. (2012). Comparing the determinants of Internet and Cell Phone Use in Africa: Evidence from Gabon. Communications and Strategies, 1(86), 65-83.

29. Sarkodieb, S. S. (2019). Contemporaneous interaction between energy consumption, economic growth and environmental sustainability in South Africa: What drives what? Science of The Total Environment, 686, 468-475.

30. Shurig, S. (2015). Who will fund the renewable solution to the energy crisis? Retrieved from http://www.theguardian.com/global-development-professionals-network/2014/jun/05/renewable-energy-electricty-africapolicy.

31. Solomon, E. M., \& Klyton, A. V. (2020). the impact of digital technology usage on economic growth in Africa. Utilities policy, 67, 101104.

32. Tchamyou, V. S. (2019). The Role of Information Sharing in Modulating the Effect of Financial Access on Inequality. Journal of African Business, 3(29), 317-338.

33. Usman, A., Ozturk, I., \& Hassan, A. M. (2020). The effect of ICT on energy consumption and economic growth in South Asian economies: An empirical analysis. Telematics and Informatics.

34. Vu K., S. .., \& Asongu., S. (2020). Backwardness advantage and economic growth in the information age: A cross-country empirical study. Technological Forecasting and Social Change, 159, 120197. 